\title{
MCT4 Upregulates PD-L1 Expression and Defines Novel Composite Therapeutic Targets for Triple- Negative Breast Cancer
}

\author{
Xianxian Duan \\ Nankai University \\ Xiao Hu \\ Nankai University \\ Zhanzhao Liu \\ Nankai University \\ Ning Li \\ Tianjin University \\ Junfang Qin \\ Nankai University \\ Lan Lan \\ Tianjin Medical University \\ Mengci Yuan \\ Nankai University \\ Yue Wang ( $\boldsymbol{\nabla}$ wangyue@nankai.edu.cn ) \\ Nankai University https://orcid.org/0000-0002-1570-5594
}

\section{Research Article}

Keywords: MCT4, PD-L1, Lactate, TNBC, pathobiology features

Posted Date: July 30th, 2021

DOl: https://doi.org/10.21203/rs.3.rs-736015/v1

License: (c) (1) This work is licensed under a Creative Commons Attribution 4.0 International License. Read Full License 


\section{Abstract}

Immune checkpoint blocking therapy targeting the PD-1/PD-L1 axis has shown promising availability for triple-negative breast cancer (TNBC). Nevertheless, in some cases, targeting efficiency is low and efficient gene interaction networks need to be sought, which inspired the exploration that MCT4 and PD-L1 coexpression network analysis and potential regulatory mechanism research. In the paper, bioinformatics, Western blot, qRT-PCR, flow cytometry, biochemical analysis, multiple immunohistochemistry, CRISPR/Cas9 and lentiviral transduction for MCT4 knockout (sgMCT4/231 KO) or overexpression (pEGFP-N1-MCT4/231) were adopted. Analysis of database basis showed MCT4 (SLC16A3) and PD-L1 (CD274) were functionally correlated and highly expressed in TNBC cells, further MCT4 and PD-L1 were co-expressed (more than $50 \%$ PD-L $1^{+} \mathrm{MCT}^{+}$cells) in tissue section of TNBC patients. The expression of PD-L1 in TNBC cell lines MDA-MB-231, MDA-MB-468 and BT-549 was sensitive to lactate concentration, and lowering MCT4 expression could downregulate PD-L1 expression through affecting the lactate concentration. These data suggests that MCT4 is positively associated with PD-L1 and the co-targeted therapy for TNBC may be a promising clinical treatment strategy.

\section{Introduction}

Triple-negative breast cancer (TNBC), defined as no estrogen receptor (ER), no progesterone receptor (PR) and no human epidermal growth factor receptor-2 (HER-2), accounts for $15-20 \%$ of all breast cancer $(\mathrm{BC})$, but is far trickier than other breast tumor molecular subtypes with poor prognosis [1-3].

Immune checkpoint blockade (ICB) has now revolutionized the treatment of cancer, notably melanoma, lymphoma, renal cell carcinoma, non-small cell lung cancer, and TNBC [4]. Immune checkpoint Programmed cell death-1 (PD-1) is mainly expressed on T cells [5], and PD-L1, a ligand of PD-1, is expressed on antigen-presenting cells as well as cancer cells, both of them mediate tumor immune escape $[4,6]$. A study of $650 \mathrm{BC}$ cases presented the positive expression rate of PD-L1 was $23.4 \%$ with reducing overall survival [7]. Similarly, a recent meta-analysis of PD-L1 in BC showed PD-L1 expression was a marker of poor prognosis [8]. One of the mechanisms of PD-L1 upregulation is the amplification of PD-L1 gene (CD274) at 9p24.1, which has been confirmed in TNBC cancer cells [9]. PD-L1 is highly expressed in melanoma and bladder cancer and its target antibody Nivolumab has been approved by the FDA for use in the treatment. Recent studies have shown that Nivolumab is also available in TNBC patients [10-12]. Lately researchers demonstrated the efficacy of PD-L1 therapy for TNBC by detecting low levels of serum PD-L1 (sPD-L1) in the patients' blood [13]. Some researchers proposed that blocking both PD-L1 and cytotoxic T-lymphocyte-associated antigen-4 (CTLA-4) were required for TNBC [14].

Monocarboxylate transporter protein 4 (MCT4) primarily mediates the transmembrane transport of proton-coupled monocarboxylic acid, such as lactate, and promotes cancer progression $[15,16]$. TNBC cells was found to exhibit a higher glycolysis rate due to high glucose uptake rate, overexpression of glycolytic enzymes, high oxygen consumption rate (OCR) and high extracellular acidification rate (ECAR) [17-19]. To excrete glycolytic wastes, MCT4 is assigned to actively express in TNBC cells [19, 20]. MCT4 
is therefore considered a carcinogenesis factor, even some pharmacologists study its structure to block it effectively [21].

It is now recognized that excess lactate and acidic tumor microenvironment (TME) can stimulate tumor angiogenesis and increase metastasis and immune escape of cancer cells [22-27], suggesting there is a connection between glycolytic metabolic molecules and the immune related molecules in cancer cells. The expression of PD-L1 has been reported to be sensitive to additional lactate [28]. Based on previous studies, we intend to study a close connection between MCT4 and PD-L1, and research the role of lactate for TNBC cells, which may provide a combination mode of blocking MCT4/PD-L1 therapy for TNBC.

\section{Materials And Methods}

\section{Gene enrichment analysis}

Gene enrichment analysis of CD274 (PD-L1) and SLC16A3 (MCT4) was performed using the Metascape online database (http://www.metascape.org/) based on the dataset retrieved from the String database (https://string-db.org/). We utilized UALCN-TCGA (The Cancer Genome Atlas) online database (http://ualcan.path.uab.edu/cgi-bin/ualcan-res.pl.) to search the expression level of MCT4 and PD-L1 in TNBC.

\section{Cell culture}

The human BC cell lines MDA-MB-231, MDA-MB-468 and BT-549 were cultured in RPMI 1640 medium (BI) with $10 \%$ fetal bovine serum. For lactate treatment, MDA-MB-231, MDA-MB-468 and BT-549 were treated with lactate for $12 \mathrm{~h}$ in high glucose DMEM (Dulbecco's Modified Eagle Medium) after starved. MCT4 inhibitor 7ACC1 (MCE, Shanghai, China) $(20 \mu \mathrm{M}, 30 \mu \mathrm{M}, 40 \mu \mathrm{M}, 50 \mu \mathrm{M}, 0.1 \mathrm{mM})$ was added to cell medium on a time gradient.

\section{Western blot (WB) analysis}

The total-cell protein was extracted by lysis buffer. The extraction of membranous and cytoplasmic protein was performed according to the kit (KeyGEN Biotech, Jiangsu, China) instructions. Protein extracted from cells was electrophoresed and transferred onto polyvinylidene fluoride (PVDF) membrane (Millipore, America). After blocked, membranes were incubated with the primary antibodies anti-MCT4 (G9) (IgG2b K, Santa Cruz Biotechnology, santa cruz, USA, 1:1500), anti-MCT4 (G-7) (IgG3 K, Santa Cruz, Santa Cruz Biotechnology, santa cruz, USA, 1:1500), anti-PD-L1 (Proteintech Group, Chicago, USA, 1:1000), anti-GAPDH (ZEN-BIOSCIENCE, 1:1000) overnight at $4^{\circ} \mathrm{C}$, and then incubated with secondary antibodies. Membranes were scanned by Tanon-5200 apparatus (Tanon, Shanghai, China) with ECL luminescence kit (Millipore, Massachusetts, USA).

\section{Wound closure assay and lactate concentration measurement}


Cells were seeded into 6 -well plate $\left(1 * 10^{6}\right.$ cells per well) and incubated for overnight at $37^{\circ} \mathrm{C}$. Different processing monolayer cells were scraped using $10 \mathrm{ml}$ pipette tips for $0 \mathrm{~h}$ and $24 \mathrm{~h}$, and image analyses of the wound closure area were conducted. The supernatant of cell culture was detected utilizing Human Lactate Elisa Kit (J\&L, Shanghai, China) for detecting lactate concentration according to the manual.

\section{Quantitative real time PCR (qRT-PCR) analysis}

Total RNA was extracted using lysis reagent Trizol kit (Vazyme, Nanjing, China), and cDNA was obtained by Hifair ${ }^{\circledR} \mathbb{1}$ st Strand CDNA Synthesis Kit (Yeasen, Shanghai, China). qRT-PCR was carried out using UltraSYBR Mixture (Cwbio, Beijing, China), and the data obtained was analysed by the $\Delta \Delta \mathrm{Ct}$ method. The primers used for qRT-PCR was listed in Table 1.

\section{CRISPR-Cas9-mediated gene editing}

MCT4 small-guide RNA (sgRNA) oligo sequences (http://crispr.mit.edu:8079/) were acquired (Table 2).

The recombinant plasmid of Lenti-CRISPR V2 was inserted with MCT4 sgRNA, and it was transfected into MDA-MB-231 cells via Lipofectamine ${ }^{\circledR} 2000$ reagent (Invitrogen, Carlsbad, California, USA) for generating MCT4 knock-out (KO) MDA-MB-231 cell line, which was selected by puromycin $(3 \mu \mathrm{g} / \mathrm{mL})$.

\section{Establishing of the stable MDA-MB-231 line expressing MCT4}

The human complementary DNA fragment encoding full-length MCT4 was cloned into pEGFP-N1 (Shanghai Gene chem, Shanghai, China). The plasmid pEGFP-N1-MCT4-wildtype(wt) was transfected into HEK-293T cell lines via Lipofectamine ${ }^{\circledR} 2000$ reagent. The virus supernatant was subsequently transfected to MDA-MB-231 cells for $48 \mathrm{~h}$ to overexpress MCT4, the infected cells were selected with Kanamycin $(50 \mathrm{ug} / \mathrm{mL})$.

\section{Immunofluorescence}

Cells grown in round glass slides were fixed by $75 \%$ alcohol and then were incubated with anti-MCT4 (G9) (Santa Cruz, 1:100) and anti-PDL1 (Proteintech, 1:100) primary antibody overnight following goat serum blocking, and then incubated with HRP-conjugated fluorescent secondary antibodies for $1 \mathrm{~h}$ and DAPI for $10 \mathrm{~min}$ at room temperature, and images were photographed by confocal microscope (Olympus, FV1000, Japan).

\section{Flow cytometry analysis}

The cells were stained by primary antibodies PDL1 (Proteintech, 1:100) and MCT4 (G-7) (Santa Cruz, 1:100) for $30 \mathrm{~min}$ and fluorescent secondary antibody for 30min respectively. The stained cells were analysed by a flow cytometer, and data obtained were presented with FlowJo software.

Hematoxylin-Eosin (HE) staining and multiple immunohistochemical staining (mlHC) 
HE staining and PD-L1, MCT4 and EpCAM staining were performed on formalin-fixed, paraffin-embedded human TNBC tumor tissue sections provided by Tianjin cancer hospital with the permission of Nankai University medical ethics committee. We trusted WiSee Biotechnology Company to perform HE and mIHC staining and assay (protocal seen as supplemental material 1), which provided simultaneous detection and quantitation of PD-L1, MCT4 and EpCAM, and we provided MCT4 (G-7) (Santa Cruz) and MCT4 (G-9) (Santa Cruz) antibody.

\section{Statistical analysis}

Statistical analyses were performed with analysis of variance (one-way ANOVA) and Student's t test using SPSS 13.0 Statistical Software (SPSS Inc., Chicago, IL, USA) and are presented as mean \pm s.d. from triplicated independent experiments. A significant difference was considered when the P-value was $<0.05$.

\section{Results}

Bioinformatics analysis revealed MCT4 and PD-L1 were functionally linked and were highly expressed in TNBC

To progressively determine the correlation of MCT4 and PD-L1 in TNBC, we adopted String online database to retrieve genes closely related to PD-L1 and MCT4 respectively, and used the Metascape online database to perform a comprehensive analysis of these two gene sets. Fig. 1a showed a dense functional overlap between the two gene sets, and the heat map of the enrichment analysis (Fig. 1b) exhibited that the two gene sets were jointly enriched in the physiological process of carbon metabolism in tumors. We then merged the two gene sets into a total set and used Metascape to generate the results again, and found that the most predominant functional enrichment of the total gene set was in PD-1 signaling (Fig. 1C). All these results indicated that PD-L1 and MCT4 were functionally related, and provided a strong theoretical basis for our subsequent experiments. We further analysed the expression level of MCT4 and PD-L1 of BC subtypes according to the French-American-British (FAB) classification based on UALCN-TCGA (The Cancer Genome Atlas) online database, and found that MCT4 and PD-L1 were specifically expressed on TNBC at mRNA level (Fig. 1d-e).

\section{mIHC of tissue samples of TNBC patients confirmed MCT4 and PD-L1 had an actively co-expression}

Further investigation about the pathological correlation of MCT4 and PD-L1 were performed in tissues of TNBC patients on the basis of molecular biological analysis. TNBC tissues with nests of glandular epithelial cells with pink cytoplasm and distinct cell borders were presented by HE staining (Fig. 2a). mIHC staining (supplemental material 1) presented the distribution and spatial location of MCT4 and PDL1 proteins. Two group images showed that compared with the stroma (top row), MCT4 and PD-L1 were both strongly expressed in the cancer tissue (bottom row) (Fig. 2b). Additionally, the statistics (supplemental material 2) presented that the ratio of MCT4 (G-7) positive cells and PD-L1 positive cells to total cells were $54.56 \%$ and $53.28 \%$, respectively, and the ratio of MCT4 (G-9) positive cells and PD-L1 positive cells to total cells were $55.84 \%$ and $55.02 \%$, respectively (Fig. 2c). A finely-ratio of 
$\mathrm{MCT}^{+} / \mathrm{PDL}^{+} / \mathrm{EpCAM}^{+}$cells to $\mathrm{EpCAM}^{+}$cells accounted for $62.50 \%$ or $62.35 \%$, respectively (Fig. $2 \mathrm{~d}-\mathrm{e}$ ). The results confirmed that MCT4 and PD-L1 were co-expressed in TNBC tissues, which also offered advisory evidence for TNBC ICB therapy.

\section{To clarify the effect of MCT4 on PD-L1 expression, MDA-MB-231 that artificially knocked down or overexpressed MCT4 were established}

To prove whether MCT4 influenced the expression of PD-L1, we altered the expression of MCT4 in TNBC cells. We firstly detected the expression of MCT4 and PD-L1 in three TNBC cell lines by WB and cellular immunofluorescence (Fig. 3a-b). Then we used CRISPR/Cas9 technology (Fig. 3c) to specifically silence the expression of MCT4 in MDA-MB-231 cells (Ctr/231), and screening a stable MCT4-silenced cell line sgMCT4/231(KO) with a silencing efficiency of $98.5 \% \pm 0.6 \%$ (Fig. 3d). Infectious lentivirus particles for MCT4 overexpression were constructed through transfecting 293T cells, and MDA-MB-231 cells were infected with the viral supernatant to obtain a stable MCT4 overexpression cell line pEGFP-N1MCT4/231 (wt), with an efficiency of $7.5 \pm 1.5$ times (Fig. 3e). Next, flow cytometry analysis displayed that the expression trend of PD-L1 was consistent with that of MCT4 in three cell lines representing Ctr/231, sgMCT4/231(KO) and pEGFP-N1-MCT4/231(wt) (Fig. 3f), which preliminarily suggested that the change of MCT4 positively affected the expression of PD-L1.

\section{Altered MCT4 expression positively affected lactate efflux and PD-L1 expression}

Given that the MCT4 KO or MCT4 overexpression are stably expressed by sgMCT4/231(KO) or pEGFP-N1MCT4/231 (wt) cells respectively and play pivotal roles in affecting lactate efflux, we analysed the expression of MCT4 by WB as shown in Fig. 4a, and detected the corresponding lactate concentration of supernatant of three cell lines and observed a significantly synchronous change in lactate concentration (Fig. 4b) as well as cell migration (Fig. 4e) with MCT4 expression. Simultaneously, we also found PD-L1 protein expression showed a trend consistent with MCT4 as shown by WB result (Fig. 4c), and so did mRNA expression (Fig. 4d), which suggested altered MCT4 expression could positively affected lactate efflux and PD-L1 expression.

\section{PD-L1 expression was sensitive to lactate in three different TNBC cell lines}

To verify the susceptibility of PD-L1 to lactate stimuli in TNBC cells, we selected five different lactate concentrations to stimulate MDA-MB-231 cells, and investigated the expression of membrane protein and total protein of PD-L1 by WB (Fig. 5a). We found that the expression of PD-L1 in MDA-MB-231 cells was sensitive to lactate, and then MDA-MB-468 and BT-549 were tested (Fig. 5b-c). The results showed that the expression of PD-L1 in protein levels, as did the mRNA expression of PD-L1 (Fig. 5d), increased significantly and showed a dependence on lactate concentrations. It suggested TNBC cell lines were sensitive to different concentrations of lactate, which could up-regulate the expression of PD-L1.

\section{MCT4 upregualted PD-L1 expression via lactate was further credited in MDA-MB-231 cells}


To further confirm that MCT4 promoted PD-L1 expression via lactate in TNBC cells, we chose the MCT4 inhibitor 7-aminocarboxycoumarins (7ACC1) [29] to specifically interfere with MCT4 expression and detected whether the lactate effluxes and PD-L1 expression was affected in representative MDA-MB-231 cells. We selected the appropriate concentrations of 7ACC1 [16] according to our previous study. Cells were treated with $7 \mathrm{ACC} 1(20 \mu \mathrm{M}, 30 \mu \mathrm{M}, 40 \mu \mathrm{M}$, and $0.1 \mathrm{mM})$ for $4 \mathrm{~h}$ and $8 \mathrm{~h}$, and the lactate concentration decreased by Elisa analysis (Fig 6a-b). Meanwhile, WB result confirmed that MCT4 expression was effectively inhibited (Fig 6c). We finally determined the optimal concentration and reaction time as $40 \mu \mathrm{M}$ and 4 hours. Then we designed experimental groups with the addition of lactate with or without the addition of 7ACC1, and we found that the trend of increased PD-L1 protein expression following lactate stimulation disappeared after MCT4 was inhibited by 7ACC1 (Fig. 6d). Although other factors could not be excluded, the positive regulating effect of MCT4 on PD-L1 could be explained. Therefore, it implied that treating TNBC patients with blocking PD-L1 immunotherapy combined with blocking MCT4 might reduce recurrence and metastasis risk of TNBC, which was probably achieved by inhibition of either lactate or tumor glycolysis (Fig. 6e).

\section{Discussion}

ICB is becoming standard treatments in several cancer types [30]. In 2019, the US Food and Drug Administration (FDA) approved the use of the blocking antibody Atezolizumab against PD-L1 combined with nab-paclitaxel for TNBC [31]. However, PD-L1 is expressed in $20 \%$ of TNBC [6], so ICB has limitations obviously. The response rate of single-agent ICB remains low and of limited durability in unselected patient populations with metastatic TNBC [32]. It is urgent to find more significant molecules as cotargets of PD-L1 to enhance the therapeutic range and efficacy of TNBC.

TNBC cell widely exhibits a metabolic phenotype with a high glycolysis [19], which negatively affects immunotherapy, for example, elevated serum lactate dehydrogenase levels in TNBC patients are associated with bad ICB therapy [33-35]. Therefore, targeting hyperglycolysis combined with ICB may improve the therapeutic efficacy of TNBC. Monocarboxylic acid transporter MCT4, responsible for lactate metabolism, is key molecules in targeting hyperglycolysis. In this study, we used the online databases UALCAN to predict the impact of MCT4 expression in BC. We found that MCT4 expression was higher in invasive $B C$ compared to normal breast tissue $(n=1211, p<1 E-12)$, and MCT4 was highly expressed in $\operatorname{TNBC}(n=833, p<0.05)$.

It was reported that the combination of ICB with the lactate reduction was beneficial to improve the treatment response of TNBC. A preclinical study showed that in tumors with high glycolysis rates, Vdomain immunoglobulin inhibitory effect on T cell activation (VISTA) was more prominent in acidic conditions. Blocking VISTA with monoclonal antibodies reversed immunosuppression, resulting in increased T-cell infiltration, inhibition of the expression of checkpoint receptors (PD-1, LAG2, and Tim-3) on T-cells, and subsequently increased antitumor activity in MC38 colorectal cancer mice [36]. These hints targeting MCT4 to reduce lactate levels is important for the treatment of ICB. 
It was reported that MCT4 and PD-L1 were consistently highly expressed in BC tissues [37], and lactate could stimulate the expression of PD-L1 in cancer cells [28]. MCT4 was a transporter of lactate to increase the extracellular lactate concentration, therefore we speculated that in TNBC cells, under the dominant regulation of MCT4, lactate might stimulate the expression of PD-L1. Analysis of database basis showed a significant functional correlation between MCT4-centered gene sets and PD-L1-centered gene sets. Together, these two genes enriched the biological functions of carbon metabolism and glycolysis and gluconeogenesis in cancer centers. Then we verified the expression of PD-L1 in overexpressed or knockdown MCT4 cell lines through a series of methods, and found that the extracellular lactate level was positively correlated with the expression level of PD-L1, and the changes in the expression of MCT4 and PD-L1 were always synchronous. This is consistent with our expectation that lactate upregulates the level of PD-L1, while MCT4 upregulates lactate, which shapes a positive feedback regulation.

More importantly, our study might contribute to the accurate differentiation of TNBC molecule subtype. According to the molecular typing published by Lehmann et al. in 2011, based on the cluster analysis of 587 TNBC gene expression profiles, TNBC were subdivided into basal-like type 1 (BL1), basal-like type 2 (BL2), immunomodulatory type (IM), mesenchymal type (M), mesenchymal stem cell type (MSL), luminal androgen receptor type (LAR), basal-like immunosuppressive type (BLIM) and mesenchymal type (MES), and in 2019, Chinese Scientist Shao et al conducted a high-throughput analysis of 465 primary TNBC samples, and classified TNBC molecule subtype into LAR, IM, BLIM and MES [38, 39]. Lehmann also developed TNBCtype online parting tools, but clinical application was still limited, more evidence was needed to refine TNBC molecule subtype for better therapeutic effect. We uncovered PD-L1 had the highest expression in TNBC IM, and more than $50 \%$ PD-L $1^{+} \mathrm{MCT} 4^{+}$cells in tissue section of TNBC patients might have a major impact on TNBC treatment. According to the 2018 ASCO/CAP guidelines, HER2 is classified as positive $\left(3^{+}\right)$with more than $10 \%$ expression in $\mathrm{BC}$ by IHC analysis, and could be treated with targeted drugs [40]. Therefore, the co-expression of PD-L1 and MCT4 in TNBC IM subtype was found to be up to $50 \%$, which is expected to become a new pathological staging or immunotherapy strategy, and is of great significance for the precision treatment of TNBC.

\section{Declarations}

Acknowledgments This work was funded by grants from the Natural Science Foundation of China (No.31770968 and 31800661), the Open Project Program of Key Laboratory for Tumor Precision Medicine of Shanxi Province (KLTPM-SX2017-A3\& KLTPM-SX2018-B1) and the Open Project Program of the Chongqing TCM key Laboratory for Metabolic Disease (Chongqing Medical University).

Conflict of interest All authors declare no conflicts of interest for this article.

\section{References}


1. Dai X, Li T, Bai Z, Yang Y, Liu X, Zhan J, et al. Breast cancer intrinsic subtype classification, clinical use and future trends. Am J Cancer Res. 2015;5(10):2929-43.

2. Thike AA, Cheok PY, Jara-Lazaro AR, Tan B, Tan P, Tan PH. Triple-negative breast cancer: clinicopathological characteristics and relationship with basal-like breast cancer. Mod Pathol. 2010;23(1):123-33. http://doi.org/10.1038/modpathol.2009.145.

3. Nedeljkovic M, Damjanovic A. Mechanisms of Chemotherapy Resistance in Triple-Negative Breast Cancer-How We Can Rise to the Challenge. Cells. 2019;8(9). http://doi.org/10.3390/cells8090957.

4. Waldman AD, Fritz JM, Lenardo MJ. A guide to cancer immunotherapy: from $T$ cell basic science to clinical practice. Nat Rev Immunol. 2020;20(11):651-68. http://doi.org/10.1038/s41577-020-0306-5.

5. Boussiotis VA. Molecular and Biochemical Aspects of the PD-1 Checkpoint Pathway. N Engl J Med. 2016;375(18):1767-78. http://doi.org/10.1056/NEJMra1514296.

6. Mittendorf EA, Philips AV, Meric-Bernstam F, Qiao N, Wu Y, Harrington S, et al. PD-L1 expression in triple-negative breast cancer. Cancer immunology research. 2014;2(4):361-70. http://doi.org/10.1158/2326-6066.CIR-13-0127.

7. Muenst S, Schaerli AR, Gao F, Daster S, Trella E, Droeser RA, et al. Expression of programmed death ligand 1 (PD-L1) is associated with poor prognosis in human breast cancer. Breast Cancer Res Treat. 2014;146(1):15-24. http://doi.org/10.1007/s10549-014-2988-5.

8. Guo Y, Yu P, Liu Z, Maimaiti Y, Wang S, Yin X, et al. Prognostic and Clinicopathological Value of Programmed Death Ligand-1 in Breast Cancer: A Meta-Analysis. PLoS One. 2016;11(5):e0156323. http://doi.org/10.1371/journal.pone.0156323.

9. Vranic S, Cyprian FS, Gatalica Z, Palazzo J. PD-L1 status in breast cancer: Current view and perspectives. Seminars in cancer biology. 2021;72:146-54.

http://doi.org/10.1016/j.semcancer.2019.12.003.

10. Disis ML, Stanton SE. Triple-negative breast cancer: immune modulation as the new treatment paradigm. Am Soc Clin Oncol Educ Book. 2015:e25-30. http://doi.org/10.14694/EdBook_AM.2015.35.e25.

11. Nanda R, Chow LQ, Dees EC, Berger R, Gupta S, Geva R, et al. Pembrolizumab in Patients With Advanced Triple-Negative Breast Cancer: Phase Ib KEYNOTE-012 Study. J Clin Oncol. 2016;34(21):2460-7. http://doi.org/10.1200/JC0.2015.64.8931.

12. Cimino-Mathews A, Foote JB, Emens LA. Immune targeting in breast cancer. Oncology (Williston Park). 2015;29(5):375-85.

13. Yazdanpanah P, Alavianmehr A, Ghaderi A, Monabati A, Montazer M, Tahmasbi K, et al. PD-L1 expression in tumor lesions and soluble PD-L1 serum levels in patients with breast cancer: TNBC versus TPBC. Breast disease. 2021;40(1):43-50. http://doi.org/10.3233/BD-201049.

14. Cabioglu N, Onder S, Oner G, Karatay H, Tukenmez M, Muslumanoglu M, et al. TIM3 expression on TILs is associated with poor response to neoadjuvant chemotherapy in patients with locally advanced triple-negative breast cancer. BMC cancer. 2021;21(1):357. http://doi.org/10.1186/s12885021-08054-6. 
15. Le Floch R, Chiche J, Marchiq I, Naiken T, Ilc K, Murray CM, et al. CD147 subunit of lactate/H+ symporters MCT1 and hypoxia-inducible MCT4 is critical for energetics and growth of glycolytic tumors. Proc Natl Acad Sci U S A. 2011;108(40):16663-8. http://doi.org/10.1073/pnas.1106123108.

16. Long Y, Gao Z, Hu X, Xiang F, Wu Z, Zhang J, et al. Downregulation of MCT4 for lactate exchange promotes the cytotoxicity of NK cells in breast carcinoma. Cancer medicine. 2018;7(9):4690-700. http://doi.org/ 10.1002/cam4.1713.

17. Pelicano H, Zhang W, Liu J, Hammoudi N, Dai J, Xu RH, et al. Mitochondrial dysfunction in some triple-negative breast cancer cell lines: role of $\mathrm{mTOR}$ pathway and therapeutic potential. Breast Cancer Res. 2014;16(5):434. http://doi.org/10.1186/s13058-014-0434-6.

18. Diers AR, Vayalil PK, Oliva CR, Griguer CE, Darley-Usmar V, Hurst DR, et al. Mitochondrial bioenergetics of metastatic breast cancer cells in response to dynamic changes in oxygen tension: effects of HIF-1alpha. PLoS One. 2013;8(6):e68348. http://doi.org/10.1371/journal.pone.0068348.

19. Doyen J, Trastour C, Ettore F, Peyrottes I, Toussant N, Gal J, et al. Expression of the hypoxia-inducible monocarboxylate transporter MCT4 is increased in triple negative breast cancer and correlates independently with clinical outcome. Biochemical and biophysical research communications. 2014;451(1):54-61. http://doi.org/10.1016/j.bbrc.2014.07.050.

20. Supuran CT. Carbonic anhydrases: novel therapeutic applications for inhibitors and activators. Nat Rev Drug Discov. 2008;7(2):168-81. http://doi.org/10.1038/nrd2467.

21. Wang $N$, Jiang $X$, Zhang S, Zhu A, Yuan $Y, X u$ H, et al. Structural basis of human monocarboxylate transporter 1 inhibition by anti-cancer drug candidates. Cell. 2021;184(2):370-83 e13. http://doi.org/10.1016/j.cell.2020.11.043.

22. Hirschhaeuser F, Sattler UG, Mueller-Klieser W. Lactate: a metabolic key player in cancer. Cancer Res. 2011;71(22):6921-5. http://doi.org/10.1158/0008-5472.CAN-11-1457.

23. Rawat D, Chhonker SK, Naik RA, Mehrotra A, Trigun SK, Koiri RK. Lactate as a signaling molecule: Journey from dead end product of glycolysis to tumor survival. Front Biosci (Landmark Ed). 2019;24:366-81.

24. Perez-Escuredo J, Dadhich RK, Dhup S, Cacace A, Van Hee VF, De Saedeleer CJ, et al. Lactate promotes glutamine uptake and metabolism in oxidative cancer cells. Cell Cycle. 2016;15(1):72-83. http://doi.org/10.1080/15384101.2015.1120930.

25. Zhang W, Wang G, Xu ZG, Tu H, Hu F, Dai J, et al. Lactate Is a Natural Suppressor of RLR Signaling by Targeting MAVS. Cell. 2019;178(1):176-89 e15. http://doi.org/10.1016/j.cell.2019.05.003.

26. Zhang D, Tang Z, Huang H, Zhou G, Cui C, Weng Y, et al. Metabolic regulation of gene expression by histone lactylation. Nature. 2019;574(7779):575-80. http://doi.org/10.1038/s41586-019-1678-1.

27. Colegio OR, Chu NQ, Szabo AL, Chu T, Rhebergen AM, Jairam V, et al. Functional polarization of tumour-associated macrophages by tumour-derived lactic acid. Nature. 2014;513(7519):559-63. http://doi.org/10.1038/nature13490.

28. Feng J, Yang H, Zhang Y, Wei H, Zhu Z, Zhu B, et al. Tumor cell-derived lactate induces TAZdependent upregulation of PD-L1 through GPR81 in human lung cancer cells. Oncogene. 
2017;36(42):5829-39. http://doi.org/10.1038/onc.2017.188.

29. Draoui N, Schicke O, Seront E, Bouzin C, Sonveaux P, Riant O, et al. Antitumor activity of 7aminocarboxycoumarin derivatives, a new class of potent inhibitors of lactate influx but not efflux. Mol Cancer Ther. 2014;13(6):1410-8. http://doi.org/10.1158/1535-7163.MCT-13-0653.

30. Gaynor N, Crown J, Collins DM. Immune checkpoint inhibitors: Key trials and an emerging role in breast cancer. Seminars in cancer biology. 2020. http://doi.org/10.1016/j.semcancer.2020.06.016.

31. Michel LL, von Au A, Mavratzas A, Smetanay K, Schutz F, Schneeweiss A. Immune Checkpoint Blockade in Patients with Triple-Negative Breast Cancer. Target Oncol. 2020;15(4):415-28. http://doi.org/10.1007/s11523-020-00730-0.

32. Kok M, Winer EP, Loi S. Passion for immune checkpoint blockade in triple negative breast cancer: Comment on the IMpassion130 study. Ann Oncol. 2019;30(1):13-6. http://doi.org/10.1093/annonc/mdy473.

33. Adams S, Schmid P, Rugo HS, Winer EP, Loirat D, Awada A, et al. Pembrolizumab monotherapy for previously treated metastatic triple-negative breast cancer: cohort A of the phase II KEYNOTE-086 study. Ann Oncol. 2019;30(3):397-404. http://doi.org/10.1093/annonc/mdy517.

34. Cona MS, Lecchi M, Cresta S, Damian S, Del Vecchio M, Necchi A, et al. Combination of Baseline LDH, Performance Status and Age as Integrated Algorithm to Identify Solid Tumor Patients with Higher Probability of Response to Anti PD-1 and PD-L1 Monoclonal Antibodies. Cancers (Basel). 2019;11(2). http://doi.org/10.3390/cancers11020223.

35. Diem S, Kasenda B, Spain L, Martin-Liberal J, Marconcini R, Gore M, et al. Serum lactate dehydrogenase as an early marker for outcome in patients treated with anti-PD-1 therapy in metastatic melanoma. Br J Cancer. 2016;114(3):256-61. http://doi.org/10.1038/bjc.2015.467.

36. Johnston RJ, Su LJ, Pinckney J, Critton D, Boyer E, Krishnakumar A, et al. VISTA is an acidic pHselective ligand for PSGL-1. Nature. 2019;574(7779):565-70. http://doi.org/10.1038/s41586-0191674-5.

37. Adams TA, Vail PJ, Ruiz A, Mollaee M, McCue PA, Knudsen ES, et al. Composite analysis of immunological and metabolic markers defines novel subtypes of triple negative breast cancer. Mod Pathol. 2018;31(2):288-98. http://doi.org/10.1038/modpathol.2017.126.

38. Jiang YZ, Ma D, Suo C, Shi J, Xue M, Hu X, et al. Genomic and Transcriptomic Landscape of TripleNegative Breast Cancers: Subtypes and Treatment Strategies. Cancer Cell. 2019;35(3):428-40 e5. http://doi.org/10.1016/j.ccell.2019.02.001.

39. Lehmann BD, Bauer JA, Chen X, Sanders ME, Chakravarthy AB, Shyr Y, et al. Identification of human triple-negative breast cancer subtypes and preclinical models for selection of targeted therapies. $J$ Clin Invest. 2011;121(7):2750-67. http://doi.org/10.1172/JCI45014.

40. Ahn S, Woo JW, Lee K, Park SY. HER2 status in breast cancer: changes in guidelines and complicating factors for interpretation. J Pathol Transl Med. 2020;54(1):34-44. http://doi.org/10.4132/jptm.2019.11.03. 


\section{Tables}

Table 1 Quantitative real time PCR primer sequences

\begin{tabular}{|ll|}
\hline Gene Name & Primer Sequences \\
\hline GAPDH (197bp) & 5'-GGAGCGAGATCCCTCCAAAAT-3'(forward) \\
\hline 5'-GGCTGTTGTCATACTTCTCATGG-3'(reverse) \\
\hline PCT4 (225bp) & 5'-CCATGCTCTACGGGACAGG-3' (forward) \\
\hline P'-GCTTGCTGAAGTAGCGGTT-3' (reverse) \\
\hline 5'-TGGCATTTGCTGAACGCATTT-3' (forward) \\
\hline 5'- TGCAGCCAGGTCTAATTGTTTT-3' (reverse) \\
\hline
\end{tabular}

Table 2 MCT4 small-guide RNA (sgRNA) oligo sequences

\begin{tabular}{|ll|}
\hline Groups & sgRNA sequences \\
\hline Negative Control & 5'-GAACGACTAGTTAGGCGTGTA-3' \\
\hline MCT4 targeting sgRNA1 & 5'-TGTTACTATCGCAGCCCTGT-3' \\
\hline MCT4 targeting sgRNA2 & 5'-GTAGGTCCCCCCGTGCACTG-3' \\
\hline
\end{tabular}

Figures 
a

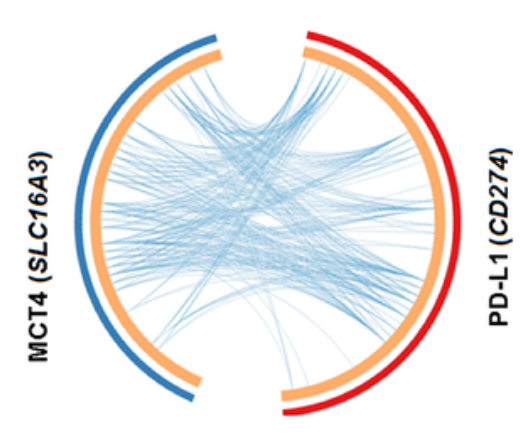

b

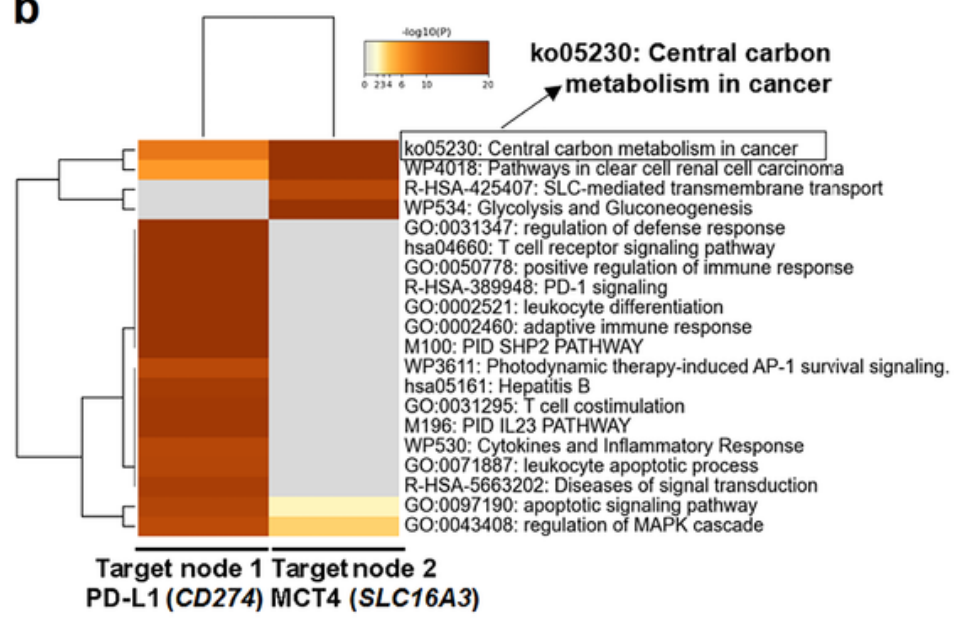

C

R-HSA-389948: PD-1 signaling

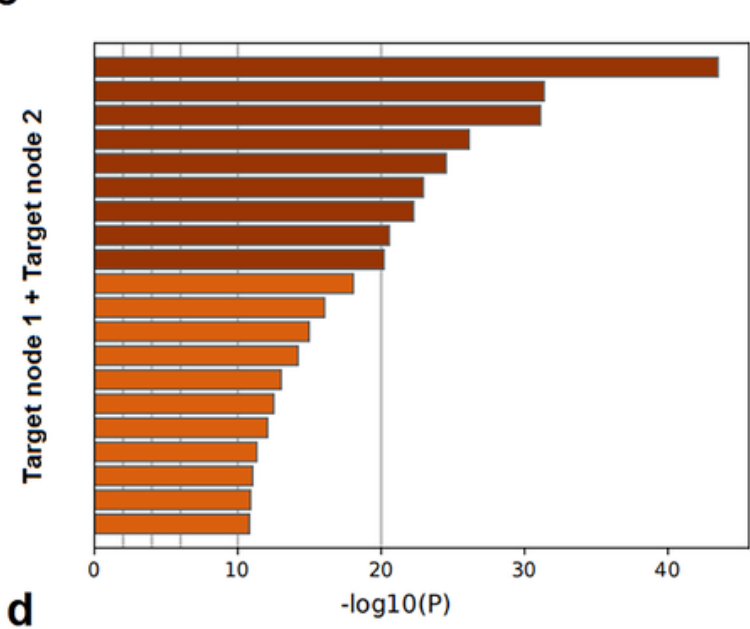

R-HSA-389948: PD-1 signaling R-HSA-1280215: Cytokine Signaling in Immune system GO:0005996: monosaccharide metabolic process M290: PID IL12 STAT4 PATHWAY GO:0042110: $T$ cell activation M255: PID HIF1 TFPATHWAY CORUM:2179: CNS-P53 complex M167: PID AP1 PATHWAY hsa00620: Pyruvate metabolism WP366: TGF-beta Signaling Pathway GO:0031295: T cell costimulation WP3888: VEGFA-VEGFR2 Signaling Pathway WP3614: Photodynamic therapy-induced HIF-1 survival hsa00030: Pentose phosphate pathway M2: PID SMAD2 3NUCLEAR PATHWAY

WP4141: PI3KJAKT/mTOR - VitD3 Signalling

GO:0032649: regulation of interferon-gamma production M66: PID MYC ACTIV PATHWAY

WP706: SIDS Susceptibility Pathways

GO:0070228: regulation of lymphocyte apoptotic process

d

Expression of SLC16A3 in BRCA based on

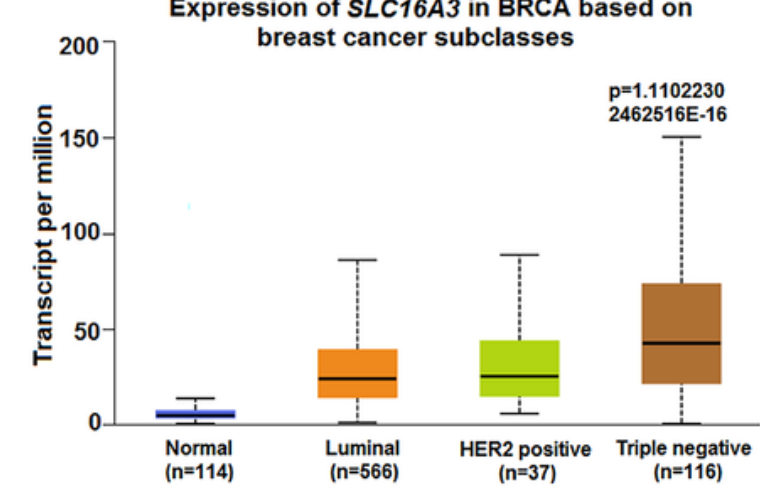

Expression of CD274 in BRCA based on
Major subclasses (with TNBC types)

TCGA samples

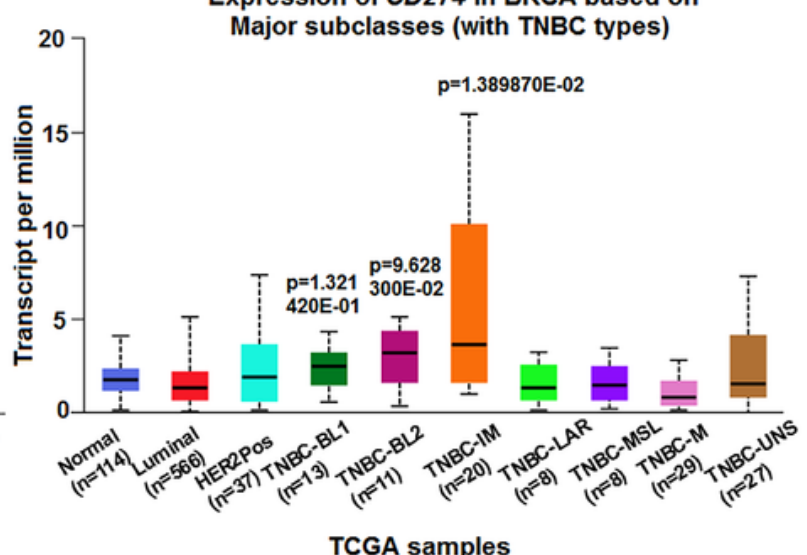

\section{Figure 1}

PD-L1 and MCT4 were functionally related. Two gene sets closely related to CD274 (PD-L1) or SLC16A3 (MCT4) were obtained from String online database. The functional association diagram (a), the heat map (b) and histogram (c) of the two gene sets appeared after being analysed via Metascape online database. Expression of MCT4 in BC based on breast cancer subclasses (d) and expression of PD-L1 in BC based on major subclasses (with TNBC types) (e) were presented through TCGA database. 
a

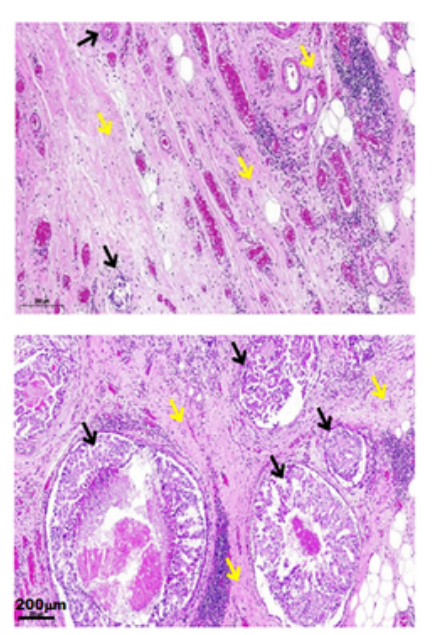

C

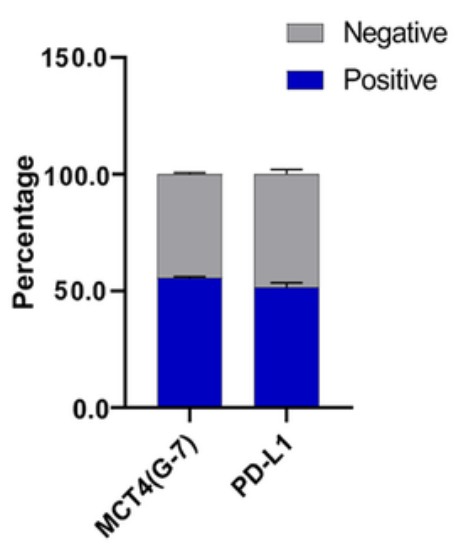

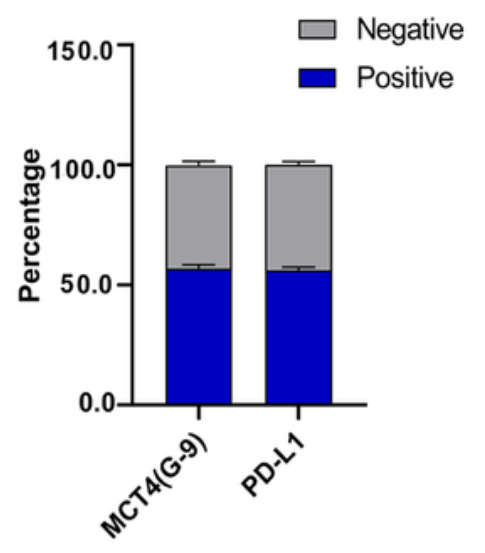

b
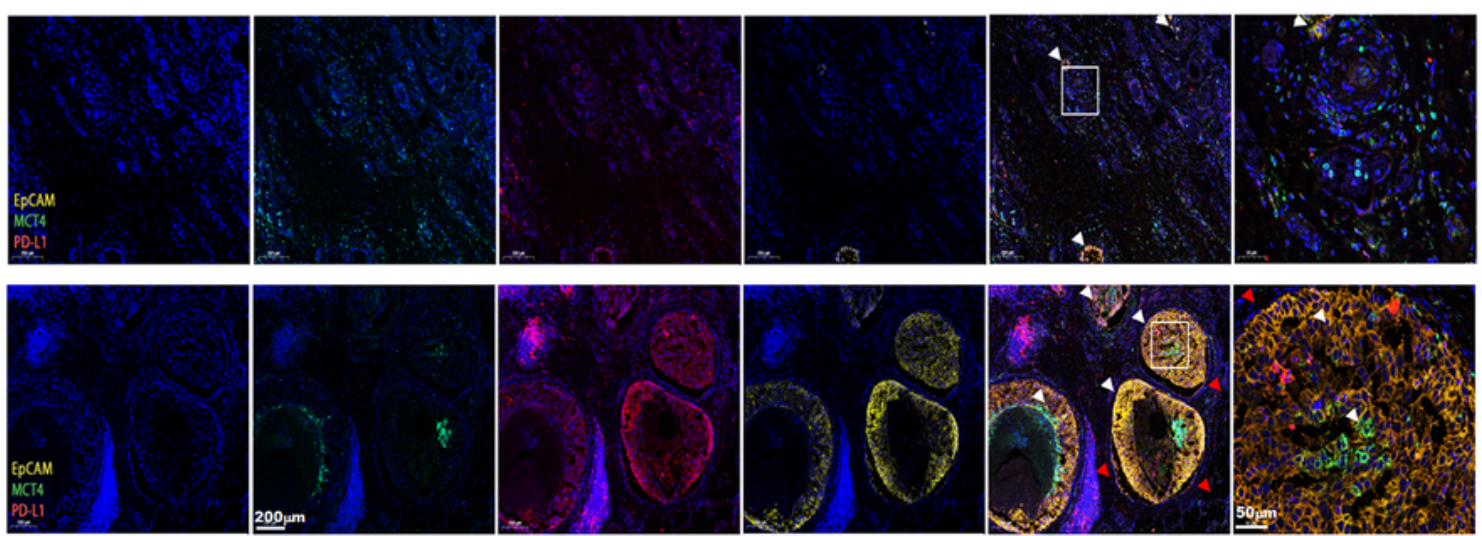

d

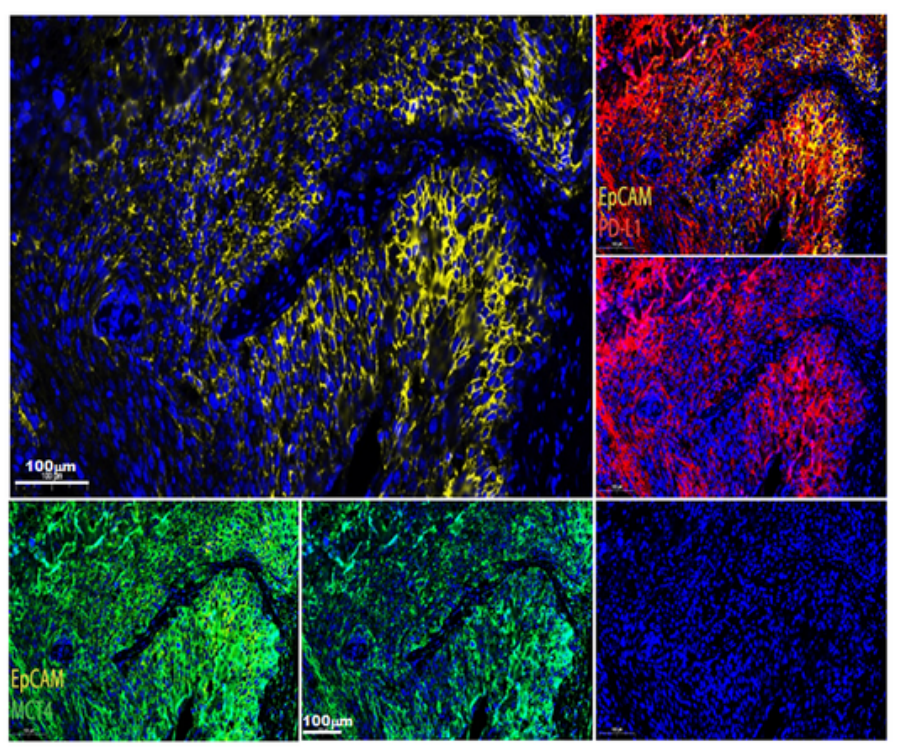

e

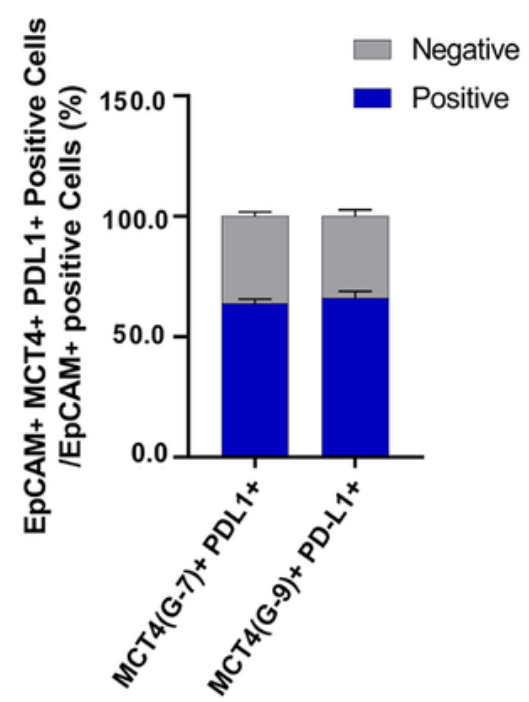

\section{Figure 2}

Pathological analysis of MCT4 and PD-L1 in TNBC tissues. (a) The nests and stroma were marked with black and yellow arrows, respectively after HE staining. (b) $\mathrm{mlHC}$ analysis images showed the distribution and spatial location of MCT4 and PD-L1 proteins and a cancer-associated antigen EpCAM. The white arrows represent cancer cell and the red arrows represent stroma. (c) Positive ratio of MCT4 (G-7 or G-9) and PD-L1 cells to total cells was higher than 50\%. MCT4 and PD-L1 proteins were highly expressed in 
EpCAM positive tissue areas (d). MCT4 and PD-L1 co-expressed cells accounted for more than $60 \%$ among the EpCAM positive cells in the tissue samples of TNBC patients (e).

a

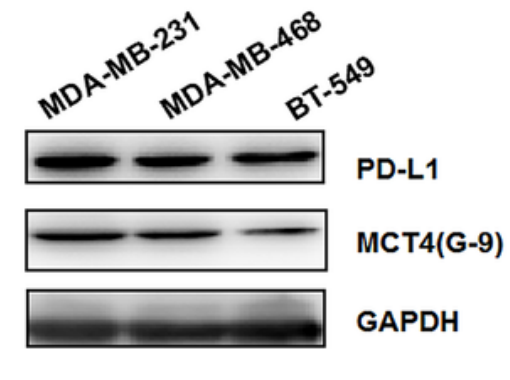

C

MCT4(SLC16A3)

cas9-sgRNA1 cas9-sgRNA2

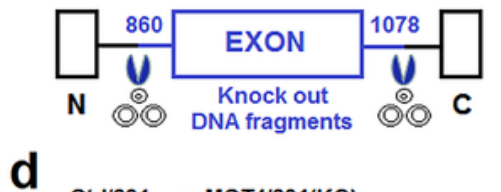

Ctrl/231 sgMCT4/231(KO)

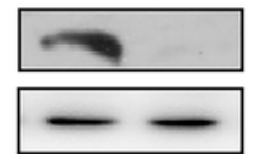

MCT4(G-9)

GAPDH
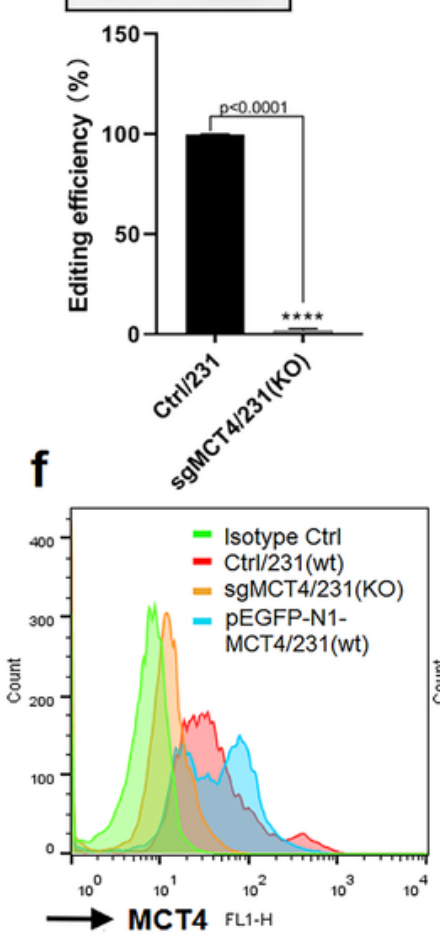

e b
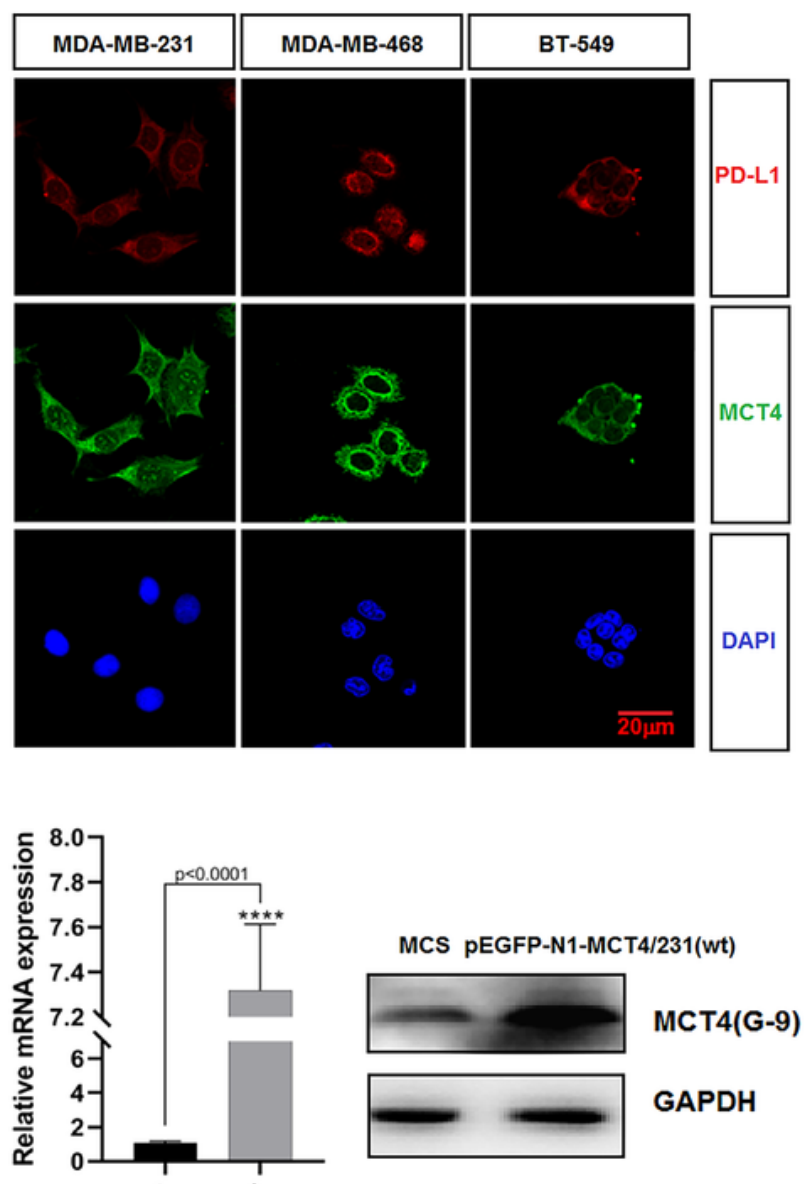

MCS pEGFP-N1-MCT4/231(wt)
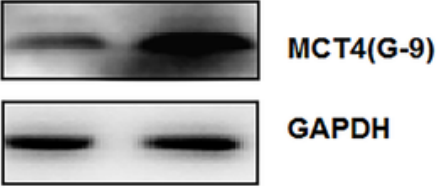

GAPDH
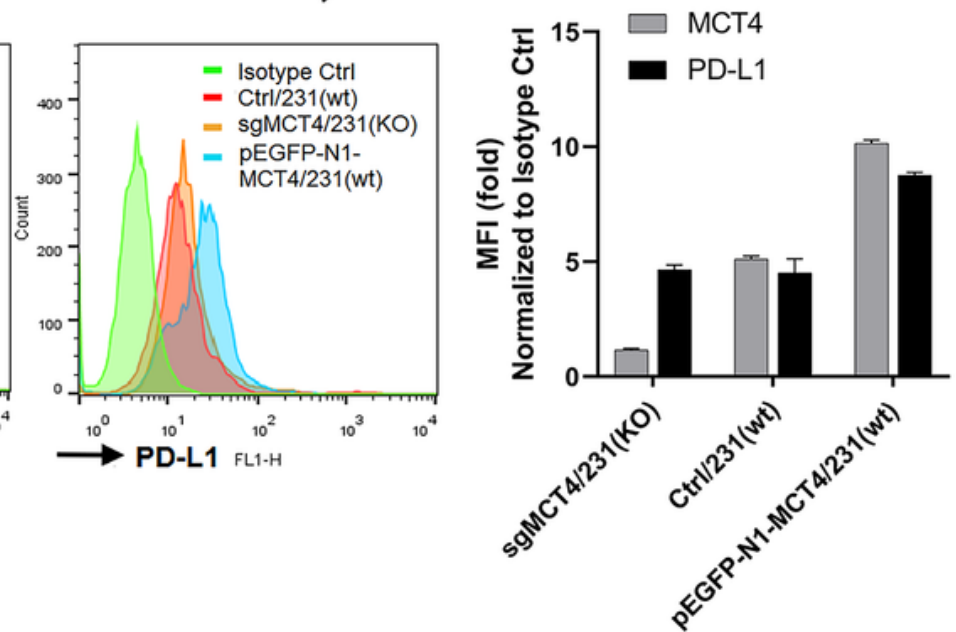

\section{Figure 3}

MCT4 was knocked or overexpressed in MDA-MB-231 to observe the corresponding change of PD-L1 expression. WB (a) and immunofluorescence (b) confirmed that PD-L1 and MCT4 were highly expressed in three TNBC cell lines and anchored to cytoplasmic membrane. Crispr/Cas9 (c) was performed to 
knock-out MCT4 in MDA-MB-231 cells and qRT-PCR (d) was used to detect knockout effect. (e) qRT-PCR and Westernblot verified the construction of pEGFP-N1-MCT4-wildtype(wt) lentiviral vector and stable MCT4 overexpression cell line pEGFP-N1-MCT4/231(wt). Flow cytometry analysis (f) was utilized to confirm the positive correlation of PD-L1 and MCT4. The results are presented as the mean \pm S.E.M. of at least three independent experiments. Statistical analysis: one-way ANOVA and T test: ${ }^{*} p<0.05$, ${ }^{\star \star \star} p<$ 0.001 .
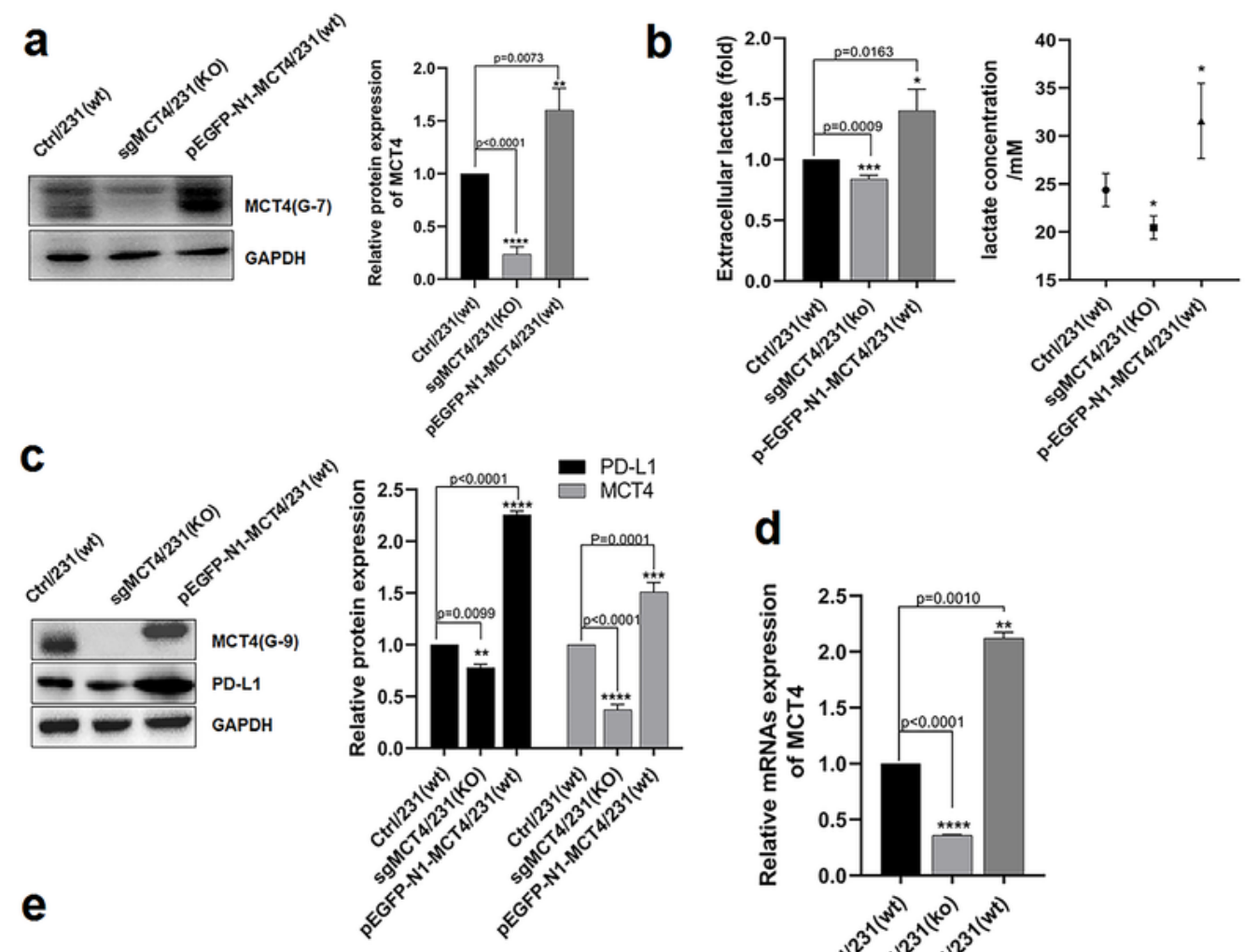

e
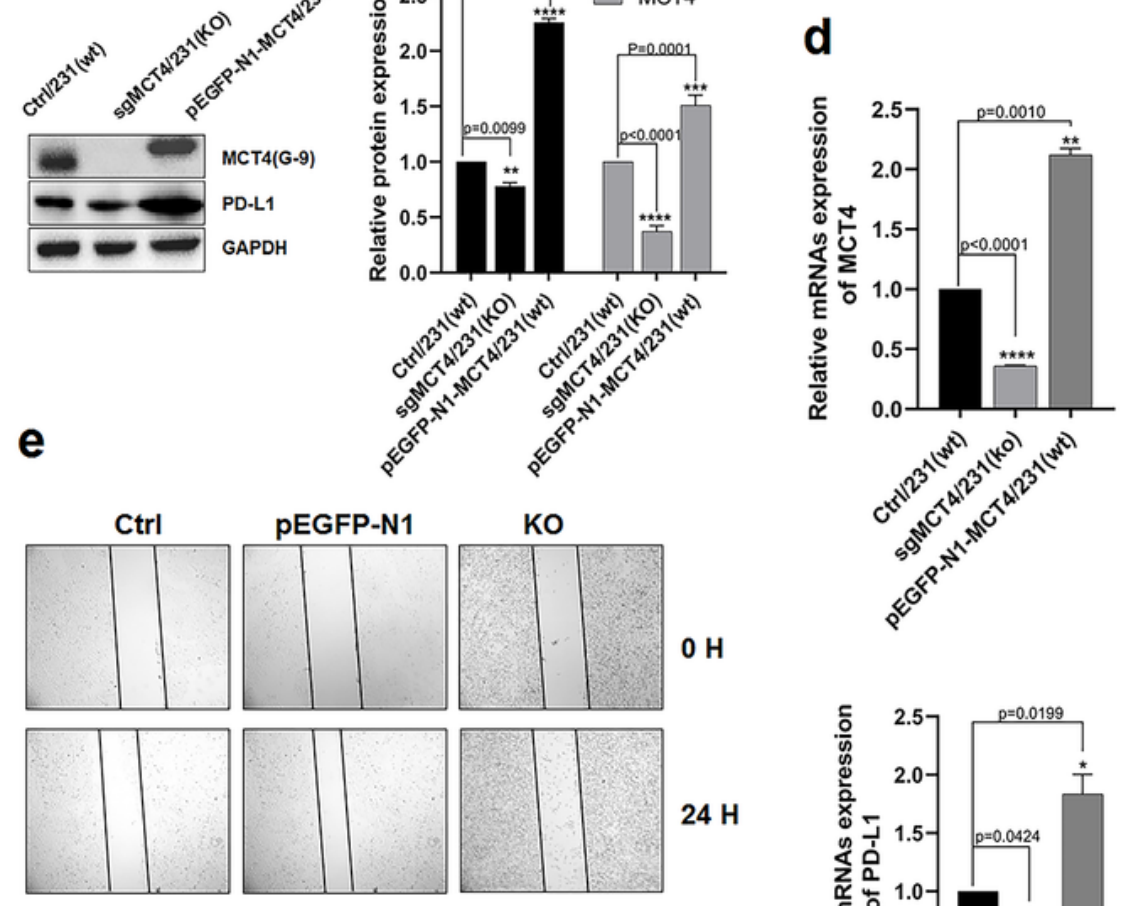

O H

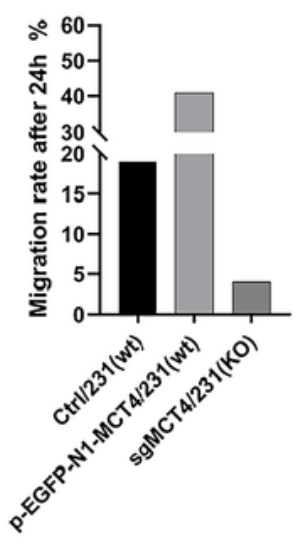

$24 \mathrm{H}$

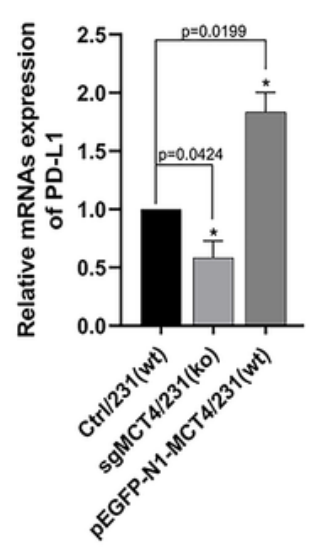

Figure 4 
The expression of PD-L1 was synchronously altered following altered MCT4 expression. WB was used to identify the expression of MCT4 in cells (a). We detected lactate concentration in medium supernatant of cells utilizing ELISA (b) and representative images and measurement of cells migration using the wound closure assay(e). WB (c) and qRT-PCR (d) were used to confirm the positive correlation of PD-L1 and MCT4. The results are presented as the mean \pm S.E.M. of at least three independent experiments.

Statistical analysis: one-way ANOVA: ${ }^{*} p<0.05, * * p<0.01,{ }^{* * *} p<0.001, * * * * p<0.0001$

a
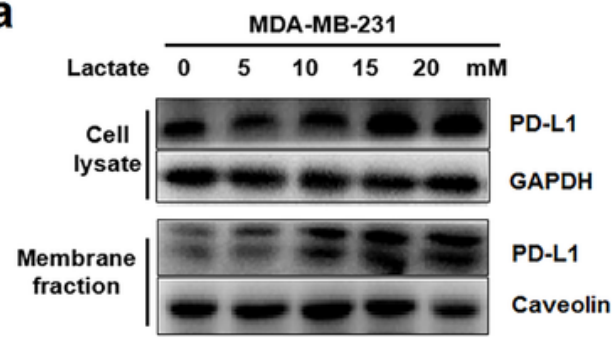

b
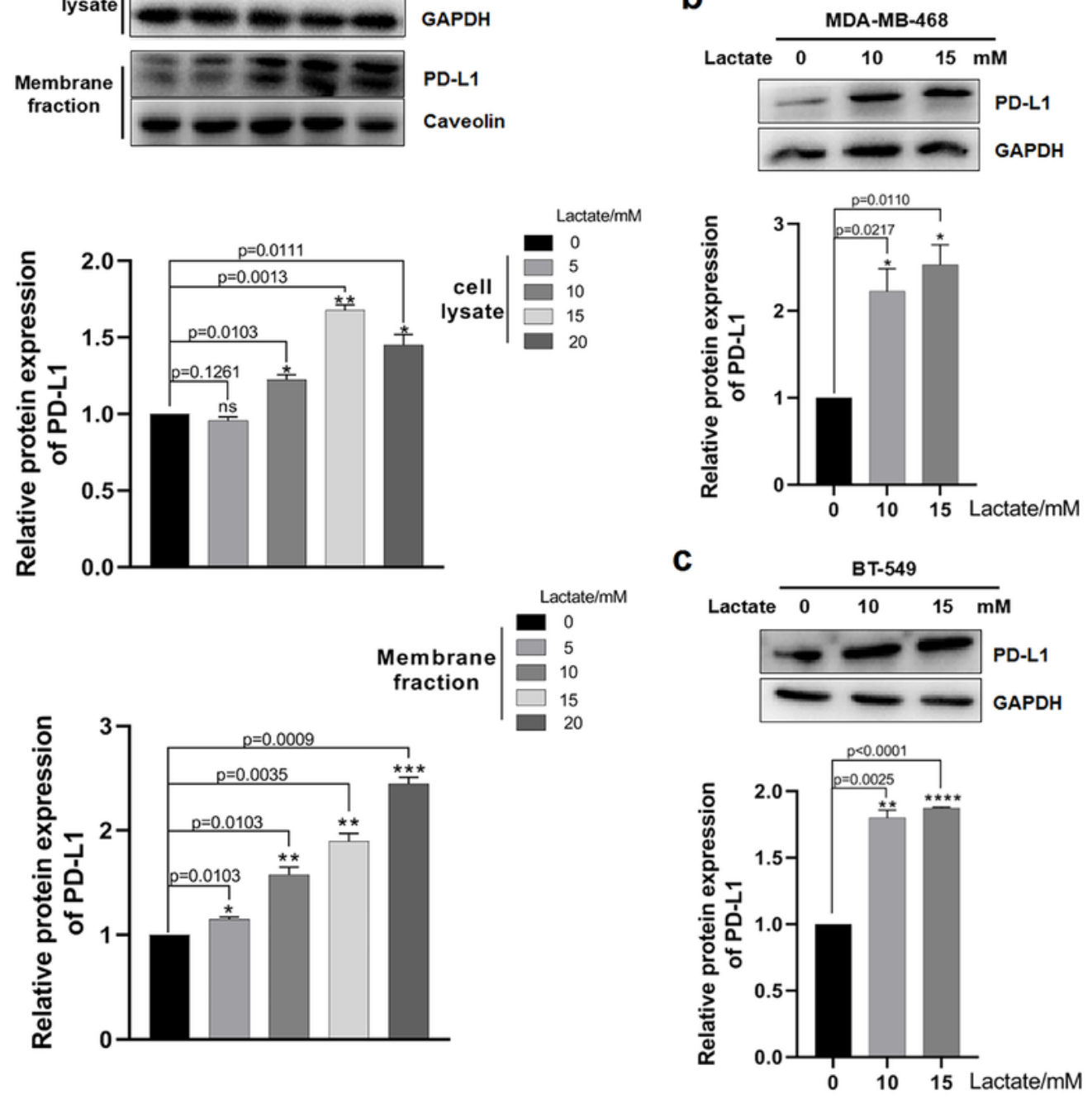

d
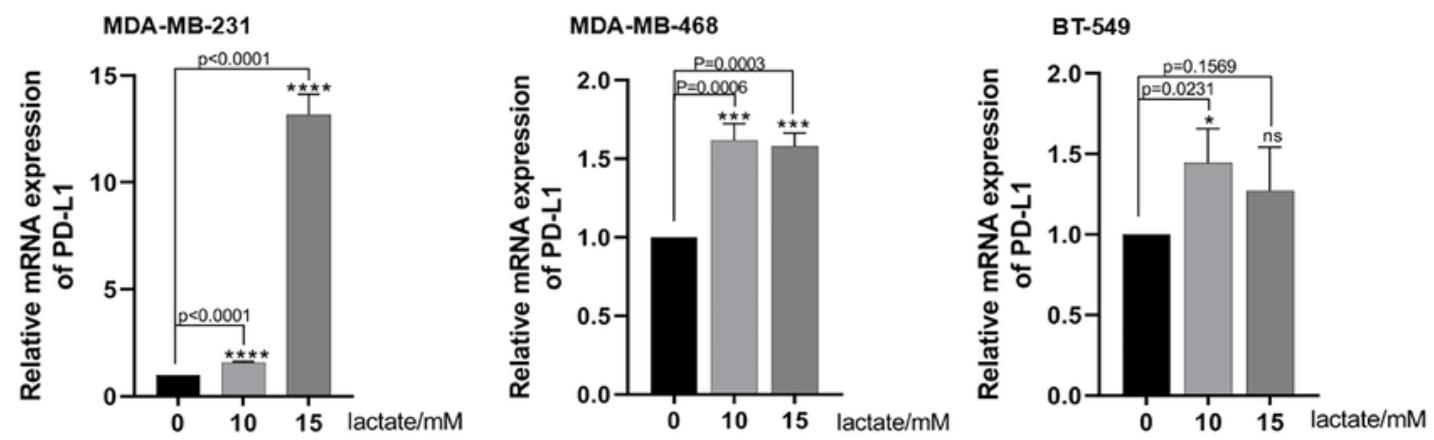

Figure 5 
The expression level of PD-L1 was upregulated with the addition of lactate. Three TNBC cell lines MDAMB-231 and MDA-MB-468 and BT-549 were treated with lactate ranging in 0, 5, 10, 15, $20 \mathrm{mM}$ concentrations after glucose starvation for $5 \mathrm{~h}$ for measure of PD-L1 expression in protein level (a-c) and mRNA level (d). The results are presented as the mean \pm S.E.M. of at least three independent experiments. Statistical analysis: one-way ANOVA: ${ }^{*} p<0.05,{ }^{* *} p<0.01, * * * p<0.001, * \star * * p<0.0001$.

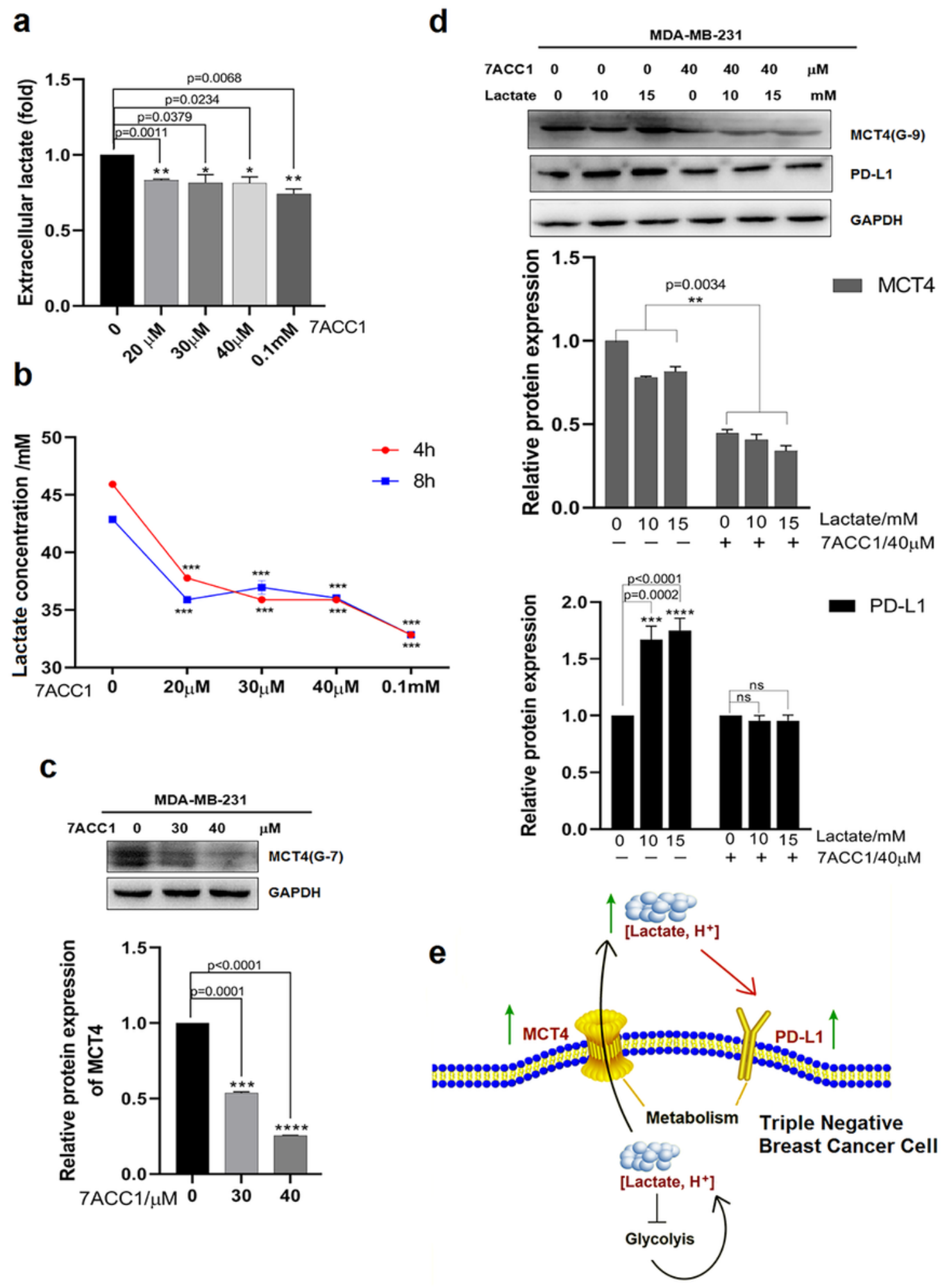

Figure 6 
Downregulated MCT4 expression inhibited by 7ACC1 inhibitor influenced the expression of PD-L1. After treating MDA-MB-231 with $7 \mathrm{ACC} 1(20 \mu \mathrm{M}, 30 \mu \mathrm{M}, 40 \mu \mathrm{M}, 0.1 \mathrm{mM})$ for $4 \mathrm{~h}$ or $8 \mathrm{~h}$, we measured extracellular lactate concentration by ELISA (a-b). WB result (c) confirmed the inhibiting effect of 7ACC1 to MCT4. MDA-MB-231 was treated with 7ACC1 $(40 \mu \mathrm{M})$ and lactate $(10 \mathrm{mM}$ and $15 \mathrm{mM})$ for $4 \mathrm{~h}$, and WB (d) was used to detect the expression of PD-L1 and MCT4. The results are presented as the mean \pm S.E.M. of at least three independent experiments. Statistical analysis: one-way ANOVA: ${ }^{*} p<0.05,{ }^{\star \star} p<0.01, * \star \star p<$ $0.001, * \star \star \star p<0.0001$. (e) Schematic of MCT4-mediated expression of PD-L1 through lactate in TNBC cell.

\section{Supplementary Files}

This is a list of supplementary files associated with this preprint. Click to download.

- supplementalmaterial1.pdf

- supplementalmaterial2.docx 